\title{
A DEONTOLOGIA COMO INSTRUMENTO DE AMPARO PROFISSIONAL NA PRÁTICA DA AVIAÇÃO: PRECISAMOS FALAR SOBRE A ÉTICA
}

\section{ARTIGO ORIGINAL}

CAROLINO, Gustavo Mateus ${ }^{1}$

CAROLINO, Gustavo Mateus. A deontologia como instrumento de amparo profissional na prática da aviação: precisamos falar sobre a ética. Revista Científica Multidisciplinar Núcleo do Conhecimento. Ano 04, Ed. 12, Vol. 05, pp. 16 24. Dezembro de 2019. ISSN: 2448-0959, Link de acesso: https://www.nucleodoconhecimento.com.br/ciencias-

\section{aeronauticas/deontologia-como-instrumento}

\section{RESUMO}

Este artigo consta de um estudo que aborda a importância de se estabelecer um código de ética e deontologia com vistas a apoiar a tomada de decisão daqueles profissionais que se ocupam da aviação e que podem praticá-la. Para tal, realizou-se uma pesquisa exploratória sobre os assuntos que permeiam a ética profissional, valendo-se de pesquisas em livros, em artigos científicos, entre outros meios que pudessem dar subsidio à esta pesquisa, visto a escassez de estudos sobre o tema na aviação. Ao final do estudo, verificou-se que um "código de ética e deontologia" é muito importante para o estabelecimento de uma profissão em seu sentido pleno e que a falta desta ferramenta na aviação afeta a cultura profissional, requerendo o assunto bastante atenção.

Palavras chave: Ética, profissional, profissionalismo, aviação, segurança, deontologia, profissão.

\footnotetext{
${ }^{1}$ Bacharel em Ciências Aeronáuticas pela Universidade FUMEC.
} 


\section{INTRODUÇÃO}

Conforme Diniz (2001 apud ANGELIN, 2010) e Freidson (1996 apud PEREIRA e NETO, 2003), o estabelecimento de uma profissão em seu significado pleno está fortemente associado à existência de um código de ética profissional: os códigos deontológicos. Entretanto, hoje, na prática profissional da aviação não se verifica a legal existência deste tipo de instrumento (CAROLINO, 2017).

Assim, tendo em vista a relevância do profissionalismo para o desenvolvimento seguro da aviação, bem como a importância da ética profissional no fenômeno da profissionalização, realizou-se o presente estudo que aborda a importância da deontologia como instrumento de amparo profissional, na organização do trabalho, na prática da aviação.

Como problema de pesquisa, levantou-se a seguinte questão:

A implantação de um código deontológico, aos profissionais que praticam aviação, pode melhorar a qualidade dos serviços prestados na prática do trabalho?

Este trabalho se justifica pela ausência de estudos que tenham como tema a ética na aviação. Buscou-se, portanto, compreender como a inexistência de mecanismos éticos legalmente estabelecidos impactam na qualidade do trabalho na prática da aviação, de uma maneira generalista, sobre a perspectiva da disciplina da ética profissional.

\section{METODOLOGIA}

Realizou-se uma pesquisa exploratória que, conforme Gil (2010), tem objetivo de proporcionar maior familiaridade com o problema, por meio de levantamento de informações, com vistas a torná-lo mais explícito ou construir hipóteses. Assim, realizou-se a delimitação do tema de interesse e a definição do problema de pesquisa. 
Em seguida realizou-se a técnica de levantamento, valendo-se de informações sobre o tema em questão, em achados contidos na bibliografia sobre o assunto, em livros, em pesquisas em artigos científicos e em outras fontes que pudessem dar subsidio à pesquisa bibliográfica, que é feita com base na literatura sobre o tema (GIL, 2010).

\section{RESULTADOS}

\section{1 ÉTICA, MORAL E DEONTOLOGIA}

A palavra ética deriva-se da palavra grega éthos que significa "modo de ser". Trata-se de uma disciplina da filosofia dedicada a estudar e explorar as vertentes da conduta humana no convívio em sociedade (MATTAR, 2010, p.240).

Dentro do campo da ética encontram-se a moral e a deontologia. A deontologia se deriva da palavra grega déon e significa "dever" ou "o que é obrigatório" sendo aplicada às profissões (MATTAR, 2010).

Ética, moral e deontologia se relacionam conforme pode-se observar no esquema representado pela Figura 1.

Figura 1 - Relação entre ética, moral e deontologia, conforme Prudente (2000 apud MATTAR, 2010)

\section{ÉTICA}

Princípios gerais

MORAL

Aplicação ao comportamento

humano e social

DEONTOLOGIA

Aplicação às profissões

Fonte: Mattar (2010, p241).

RC: 42748

Disponível em: https://www.nucleodoconhecimento.com.br/ciencias-aeronauticas/deontologiacomo-instrumento 
Em deontologia, o verbo dever no imperativo indica o modo de ser obrigatório o qual alguém deve se comportar de modo a participar corretamente de um determinado grupo profissional. Esses códigos deontológicos são legalmente estabelecidos por meio dos próprios profissionais, detentores de uma determinada profissão (MATTAR, 2010).

Portanto, verificou-se que os códigos de deontologia são tratados que definem parâmetros éticos que regem princípios de deveres de observância obrigatória em profissões (MATTAR, 2010).

\subsection{RELEVÂNCIA DA ÉTICA PROFISSIONAL PARA AS PROFISSÕES}

Quando uma profissão é estabelecida, ela atua como um filtro garantidor de que a realização de determinados serviços na sociedade possa ser conduzida de maneira segura e responsável, se por determinados profissionais forem eles realizados. Nesse contexto, o estabelecimento de uma profissão em seu significado pleno está associado, entre outros atributos, ao conhecimento técnico-científico, à autorregulação profissional e à existência de um código de ética profissional (ANGELIN, 2010).

A existência de tratados éticos favorece o profissionalismo, pois, conforme Machado (2009), a atuação profissional pode então ser norteada por um repertório de valores socialmente acordados, apoiados em princípios fundamentais que ultrapassam em muito a busca do lucro ou de um mero benefício pessoal do agente ao realizar um determinado trabalho, o que favorece tomadas de decisões éticas.

Conforme Mattar (2010), no caso de descumprimento dos códigos deontológicos, são previstas sanções ao infrator que podem levar, inclusive, à perda da capacidade legal de exercer uma determinada profissão, protegendo a sociedade e os próprios profissionais - realmente compromissados com os valores de uma determinada profissão - de possíveis desvios dentro do grupo profissional. 


\subsection{A TOMADA DE DECISÃO ÉTICA PROFISSIONAL E A AVIAÇÃO}

A tomada de decisão é um processo cognitivo que envolve a avaliação e a escolha de uma alternativa dentre várias opções de conduta (STERNBERG, 2000). Assim, como explica Honorato (2014) em sua obra, uma ação pode ser o meio necessário para assegurar, por exemplo, o cumprimento de deveres de cuidados que dos profissionais da aviação são exigidos.

Sugere-se, entretanto, que as condutas aceitáveis ou inaceitáveis do ponto de vista da ética profissional não sejam bem definidas na prática da aviação, pois, como exposto, falta aos profissionais que praticam aviação um código deontológico legalmente estabelecido (CAROLINO, 2017).

Desenvolver habilidades, competências e atitudes éticas, segundo Mattar (2010, p.240), implicará em "ser capaz de identificar, em cada situação, o que é essencial para a tomada de decisões, principalmente no caso de situações complexas".

\section{DISCUSSÃO}

A existência de um código de ética e deontologia é muito importante para o estabelecimento de profissões (DINIZ, 2001 apud ANGELIN, 2010; FREIDSON, 1996 apud PEREIRA e NETO, 2003). Entretanto, o presente estudo não identificou a existência de um código deontológico legalmente vigente aos profissionais que praticam aviação, o que indica que ainda não há oficializado uma profissão em seu significado pleno voltada a professar aviação.

Como exposto por Mattar (2010), os códigos deontológicos são tratados que definem parâmetros éticos que regem princípios de deveres de observância obrigatória no exercício de profissões. A existência destes códigos favorece o profissionalismo, pois, conforme Machado (2009), com sua implantação a atuação profissional passa a ser norteada por um repertório de valores socialmente acordados, apoiados em princípios fundamentais que ultrapassam em muito a busca do lucro ou de um mero benefício 
pessoal do agente ao realizar um determinado trabalho, orientando tomadas de decisões éticas nessa atuação.

Nesse contexto, verificou-se que o próprio compromisso público que os profissionais assumem ao professar uma determinada profissão na sociedade torna necessária a efetivação de um mecanismo de autorregulação profissional. É por meio desse tipo de mecanismo que se torna possível a criação, a implantação e a manutenção de um legal "código de ética e deontologia" que, conforme exposto por Mattar (2010), deve ser estabelecido por meio dos próprios profissionais, detentores de uma determinada profissão.

Como exposto neste trabalho, na aviação, o exercício profissional está relacionado a constantes tomadas de decisões com vistas a assegurar, por exemplo, o cumprimento dos deveres de cuidado que dos profissionais são exigidos. Assim, a tomada de decisão caracteriza-se, neste contexto, como um processo cognitivo, as vezes complexo, que é necessário para a resolução de problemas, e se baseia na escolha entre opções de modos de proceder a fim de atingir um objetivo.

Entretanto, sugere-se que a tomada de decisão ética profissional não é bem definida no contexto profissional da aviação, uma vez que até os dias de hoje inexiste um código deontológico legalmente instituído para a prática aviatória (CAROLINO, 2017). Sua existência poderia proporcionar orientações sobre aspectos da disciplina e da conduta profissional, apoiando a tomada de decisão ética-profissional.

Assim, conforme levantado, a busca por mecanismos éticos que orientem e disciplinem a prática do trabalho profissional é de grande importância para avançar no desenvolvimento e na organização de uma forte e segura cultura profissional, em que se possa apoiar o bom profissional. A existência de um código de ética profissional também pode melhor clarear os modos errados de condutas que possam ser consideradas inaceitáveis, por decorrerem, por exemplo, de "desvios da ideia de profissionalismo"[2], requerendo a adoção de medidas corretivas, portanto, sejam elas educacionais, administrativas e/ou, até mesmo, jurídicas. 


\section{CONCLUSÃO}

Como exposto neste trabalho, hoje, profissionais que praticam aviação trabalham desprovidos de princípios éticos profissionais legalmente acordados por meio de códigos deontológicos. Por essa razão, verificou-se não existir oficializada uma profissão em seu sentido pleno destinada a professar aviação, fato que requer bastante atenção.

Ao responder à questão problema desta pesquisa, verificou-se que a qualidade da prática profissional da aviação pode ser melhorada com a implantação deste tipo de código, uma vez que tais normas de ética profissional fortalecem a cultura do profissionalismo. Isso ocorre, pois, conforme exposto por Machado (2009), a atuação profissional passaria a ser norteada por um repertório de valores socialmente acordados, apoiados em princípios fundamentais que ultrapassam em muito a busca do lucro ou de um benefício pessoal do agente em realizar determinado trabalho, favorecendo tomadas de decisões éticas nessa atuação.

Verificou-se também que o próprio compromisso público que os profissionais assumem ao professar uma profissão, em seu significado pleno, requer a implantação de um mecanismo de autorregulação profissional. É por meio dessa autorregulação que se torna possível o estabelecimento de um legal e formal "código de ética e deontologia" para orientar a profissão.

Por tudo isso, recomenda-se a adoção de um legal código de ética profissional aos profissionais que praticam aviação, a exemplo dos dispositivos sugeridos no apêndice A ao final deste trabalho.

\section{REFERÊNCIAS}

ANGELIN, Paulo Eduardo. Profissionalismo e profissão: teorias sociológicas e o processo de profissionalização no Brasil. Revista REDD, v.3, n.1. 2010. Disponível em $<$ http://seer.fclar.unesp.br/redd/article/view/4390>. Acesso em 28 de julho de 2017. 
CAROLINO, Gustavo Mateus. A profissionalização da prática da aviação: uma abordagem exploratória sobre os rumos do contexto profissional no Brasil. Revista Conexão Sipaer. Vol. 8, No. 1, pp. 3-9. 2017. Disponível em: <http://conexaosipaer.cenipa.gov.br/index.php/sipaer/article/view/403/347 >. Acesso em 28 de julho de 2017.

GIL, Antônio Carlos. Como elaborar projetos de pesquisa. 5. Ed. São Paulo: Atlas, 2010. 184p.

HONORATO, Marcelo. Crimes Aeronáuticos. Brasil. Ed. Lúmen Juris Ltda. 2014. ISBN 978-85-8440-032-4

MACHADO, Nilson José. Competência e profissionalismo: o lugar da ética. Programa ética e cidadania - construindo valores na escola e na sociedade. Programa Ética e Cidadania. Brasil. 2009. Disponível em <http://www.letras.ufmg.br/espanhol/pdf/\%C3\%89tica\%20e\%20cidadania/O\%20lugar \%20da\%20\%C3\%A9tica.pdf >. Acesso em 28 de julho de 2017.

MATTAR, João. Introdução à filosofia. Ed. Pearson. 2010. ISBN 978-85-7605-6973

PEREIRA, Fernanda Martins; NETO, André Pereira. O psicólogo no Brasil: notas sobre seu processo de profissionalização. Psicologia em Estudo. Maringá. v.8, n. 2, p.19-27. 2003. Disponível em < http://www.scielo.br/pdf/pe/v8n2/v8n2a02 >. Acesso em 28 de julho de 2017.

STERNBERG, Robert J.. Tomada de decisão e raciocínio. Cap.12. In Sternberg, R.J. (Ed.). Psicologia cognitiva (pp. 339-370). Porto Alegre: Artmed. 2000.

\section{APÊNDICE - REFERÊNCIA DE NOTA DE RODAPÉ}

2. Conforme Machado (2012 apud CAROLINO, 2017, p.5), são exemplos de desvios da ideia de profissionalismo, condutas amadoras e mercenárias. 


\section{APÊNDICE A - RECOMENDAÇÃO PARA A SEGURANÇA DA AVIAÇÃO}

\section{Recomendação para a segurança da aviação:}

Com vistas a estimular futuros trabalhos enfocados na viabilização de um legal e formal "código de ética e deontologia" para a aviação, principalmente tendo como objetivo oficializar a plena profissão da aviação, e em observância aos achados neste trabalho, recomenda-se a apreciação das seguintes sugestões de deveres éticos de observância obrigatória para professar a aviação:

O aviador ou a aviadora deve:

I - Proceder de forma que o (a) torne merecedor (a) de respeito e que contribua para o prestígio da profissão e da aviação.

- Nenhum receio de desagradar o operador, explorador ou qualquer autoridade, nem de ocorrer em impopularidade, deve deter o (a) aviador (a) de realizar as medidas necessárias para a garantia do estado de segurança da prática da aviação.

II - Preservar em sua conduta a honra, a nobreza e a dignidade da profissão.

III - Atuar com honestidade, decoro, veracidade, lealdade, dignidade e boa-fé.

IV - Velar por sua reputação profissional.

V-Empenhar-se em seu aperfeiçoamento pessoal e profissional.

VI - Contribuir para o aprimoramento das instituições, da aviação, ciência e tecnologia.

VII - Repassar ao (à) seu (sua) substituto (a) as informações necessárias à continuidade dos trabalhos. 
VIII - Apresentar à justiça, quando convocado na qualidade de perito (a) ou na qualidade de testemunha, as conclusões do seu laudo ou de seu depoimento, sem extrapolar o âmbito da competência profissional e sem violar os princípios éticos profissionais em vigor.

IX - Respeitar as Leis e normas estabelecidas para o legal exercício da profissão.

Enviado: Agosto, 2019.

Aprovado: Dezembro, 2019. 